\title{
Binge-Like Alcohol Exposure During Adolescence Disrupts Dopaminergic Neurotransmission in the Adult Prelimbic Cortex
}

\author{
Heather Trantham-Davidson, ${ }^{* 1,5}$, Samuel W Centanni ${ }^{1,5}$, S Corrin Garr', Natasha N New', \\ Patrick J Mulholland', Justin T Gass', Elizabeth J Glover', Stan B Floresco ${ }^{2}$, Fulton T Crews ${ }^{3}$, \\ Harish R Krishnan ${ }^{4}$, Subhash C Pandey ${ }^{4}$ and L Judson Chandler'
}

'Department of Neuroscience, Medical University of South Carolina, Charleston, SC, USA; ${ }^{2}$ Department of Psychology and Brain Research Centre, University of British Columbia, Vancouver, BC, Canada; ${ }^{3}$ Bowles Center for Alcohol Studies, University of North Carolina at Chapel Hill, Chapel Hill, NC, USA; ${ }^{4}$ Department of Psychiatry, University of Illinois at Chicago and Jesse Brown VA Medical Center, Chicago, IL, USA

\begin{abstract}
Repeated binge-like exposure to alcohol during adolescence has been reported to perturb prefrontal cortical development, yet the mechanisms underlying these effects are unknown. Here we report that adolescent intermittent ethanol exposure induces cellular and dopaminergic abnormalities in the adult prelimbic cortex (PrL-C). Exposing rats to alcohol during early-mid adolescence (PD28-42) increased the density of long/thin dendritic spines of layer 5 pyramidal neurons in the adult PrL-C. Interestingly, although AIE exposure did not alter the expression of glutamatergic proteins in the adult PrL-C, there was a pronounced reduction in dopamine (DA) D, receptor modulation of both intrinsic firing and evoked NMDA currents in pyramidal cells, whereas $\mathrm{D}_{2}$ receptor function was unaltered. Recordings from fast-spiking interneurons also revealed that AlE reduced intrinsic excitability, glutamatergic signaling, and D, receptor modulation of these cells. Analysis of PrL-C tissue of AlE-exposed rats further revealed persistent changes in the expression of DA-related proteins, including reductions in the expression of tyrosine hydroxylase and catechol-O-methyltransferase (COMT). AlE exposure was associated with hypermethylation of the COMT promoter at a conserved CpG site in exon II. Taken together, these findings demonstrate that AlE exposure disrupts DA and GABAergic transmission in the adult medial prefrontal cortex (mPFC). As DA and GABA work in concert to shape and synchronize neuronal ensembles in the PFC, these alterations could contribute to deficits in behavioral control and decisionmaking in adults who abused alcohol during adolescence.

Neuropsychopharmacology (2017) 42, I024-1036; doi:I0.1038/npp.2016.190; published online I4 December 2016
\end{abstract}

\section{INTRODUCTION}

Alcohol is the most widely used drug during adolescence, and is abused more than all other drugs combined (Witt, 2010). Alcohol consumption in this age group typically occurs in excessive binge-like patterns that are often associated with high levels of intoxication. Adolescence is characterized as a period of increased impulsivity, exploratory drive and risk taking. These behaviors appear to relate to delayed development of the inhibitory control processes of the brain that are mediated by the prefrontal cortex (PFC). The PFC is developmentally unique in that it matures at a much slower rate compared with other brain regions and undergoes extensive synaptic pruning during adolescence

*Correspondence: Dr H Trantham-Davidson, Department of Neuroscience, Medical University of South Carolina, 67 President Street, IOPN 465, MSC86I, Charleston, SC 29425, USA, Tel: + I 843 792 5206, E-mail: tranthah@musc.edu

${ }^{5}$ The first two authors contributed equally to this work.

Received 26 February 2016; revised 5 August 2016; accepted 7 September 2016; accepted article preview online 13 September 2016 before stabilizing in the third decade of life (Casey and Jones, 2010; Petanjek et al, 2011). The enhanced capacity of the adolescent PFC to undergo structural and functional modifications may render it especially vulnerable to environmental insults such as those associated with repeated episodes of binge-like alcohol exposure. In addition to impacting the brain and behavior at the time of use, adolescent alcohol abuse may also have long-lasting detrimental effects on the PFC that extend well into adulthood. Human studies of adults who abused alcohol during adolescence have found smaller prefrontal grey and white matter volumes compared with age-matched controls (De Bellis et al, 2005; Welch et al, 2013). Reduced prefrontal volume is associated with deficits in inhibitory control, poor decision making, and increased propensity to engage in risky behaviors (Dalwani et al, 2011).

Medial PFC (mPFC) function is mediated by excitatory recurrent activation of network ensembles of pyramidal neurons that is temporally and spatially limited by inhibitory, parvalbumin-positive fast-spiking interneurons (FSINs). The dense dopaminergic projection to the deep layers of 
mPFC refines and sculpts the activity of both cell types via stimulation of $\mathrm{D}_{1}$ and $\mathrm{D}_{2}$ receptors, increasing or decreasing intrinsic excitability and synaptic transmission accordingly. In parallel with maturation of cognitive function that occurs during adolescence, GABAergic networks and dopaminergic inputs to the mPFC undergo significant pruning that is also accompanied by changes in dopamine (DA) receptor function (Tseng and O'Donnell, 2007; Teicher et al, 1995; Naneix et al, 2012).

Adolescence represents a critical period for the development of dopaminergic and GABAergic signaling within the $\mathrm{PFC}$, and perturbations of this process induced by alcohol exposure during adolescence would be expected to result in deficits in prefrontal-mediated cognition that may persist or be expressed in adulthood. This suggestion is consistent with considerable preclinical evidence showing that adolescent alcohol exposure impairs multiple aspects of executive functioning. For example, using a rat model of adolescent intermittent alcohol exposure, we recently reported that binge-like alcohol exposure during adolescence results in deficits in PFC-mediated behavioral control when tested in adulthood (Gass et al, 2014). Similar treatments have also been reported to impair working memory (Schulteis et al, 2008), and Vargas et al (2014) observed that the amount of alcohol consumed by adolescent rats in a binge drinking procedure predicted poorer working memory performance in adulthood. Similarly, adult animals exposed to alcohol during adolescence showed impairments in temporal order recognition memory (Swartzwelder et al, 2015). Notably, each of the above-mentioned functions that are impaired by early alcohol exposure are critically dependent on the integrity of the $\mathrm{mPFC}$, as well as dopaminergic D1 receptor and GABA transmission within this region (Hannesson et al, 2004; Enomoto et al, 2011; Floresco, 2013; Lejeune et al, 2013; Tse et al, 2015; Auger and Floresco, 2015).

In light of the considerable evidence that adolescent alcohol exposure impairs numerous prefrontal functions during adulthood, a primary aim of the present study was to obtain insight into the pathophysiological alterations of morphological, neurochemical, and electrophysiological properties of mPFC neurons. We used a well-established model of alcohol exposure that we have previously shown to impair cognitive flexibility (Gass et al, 2014), and placed a primary emphasis on how this early insult alters neuronal activity, and dopaminergic and GABAergic neurotransmission in the adult prelimbic region of the MPFC (PrL-C).

\section{MATERIALS AND METHODS}

\section{Animals and Ethanol Vapor Exposure}

Male Long-Evans rats were bred in-house (Charles River breeding stock), weaned at postnatal day 21 , and subjected to intermittent ethanol exposure beginning at PD28 and ending at PD42. All experimental procedures were conducted with the approval of the Institutional Animal Care and Use Committee at the Medical University of South Carolina, and within guidelines set forth by the National Research Council's Guide for the Care and Use of Laboratory Animals (2003). The adolescent intermittent ethanol exposure model used in the present study involved intermittent binge-like exposure to alcohol by vapor inhalation as described previously (Gass et al, 2014). A detailed description of the experimental groups, housing conditions, and adolescent ethanol vapor exposure procedure can be found in Supplementary Materials.

\section{Dendritic Spine Imaging and 3D Analysis}

Diolistic labeling of slices obtained from fixed brains was used to assess the effects of AIE exposure on dendritic spine morphology in the PrL-C following previously published procedures (Kroener et al, 2012) and described in detail in Supplementary Materials.

\section{Immunoblotting and Slice Immunohistochemistry}

Standard immunoblotting and immunohistochemistry procedures were used to examine the effect of AIE exposure on protein expression in the adult PrL-C. Detailed information on these procedures is provided in Supplementary Materials.

\section{MB-COMT Promoter Methylation}

Tissue punches containing the PrL-C were obtained for immunoblotting as described in Supplementary Materials and temporarily stored at $-80^{\circ} \mathrm{C}$. Genomic DNA was obtained using the QIAGEN DNeasy Blood and Tissue Kit (cat. no. 69504; Qiagen, Valencia, CA) following the manufacturer's protocol and methylation of the promoter region of membrane-bound catechol-O-methyltransferase (MB-COMT) was measured as described in Supplementary Materials.

\section{Electrophysiological Recordings}

Acute slices were obtained for electrophysiological recordings from AIE- and air-exposed control rats between PD90 to PD120 and current- and voltage-clamp recordings were performed as described in Supplementary Materials.

\section{RESULTS}

\section{AIE Alters Dendritic Spine Density and Morphology}

Adolescent rats were subjected to either ethanol vapor or air exposure from PD28 to PD42 (Supplementary Table S1). To determine if AIE altered PFC pyramidal neuron morphology in adulthood, diolistic labeling coupled with confocal imaging and $3 \mathrm{D}$ image analysis was used to examine the density and morphology of dendritic spines of layer $\mathrm{V}$ pyramidal neurons in the PrL-C. As shown in Figure 1, there was a significant increase in overall spine density following AIE $\left(\mathrm{F}_{(1,18)}=4.6, p<0.05\right)$. Classification of spine density based on morphology revealed that the increase was due to a significant increase in the density of long spines with no change in the density of stubby or mushroom spines $\left(\mathrm{F}_{(2,36)}=5.5, p<0.01\right.$; Tukey's post hoc, $\left.p<0.01\right)$.

As a follow-up to examination of the structural changes in dendritic spines of glutamatergic synapses, the next set of studies examined changes in NMDA and AMPA receptors in AIE-exposed rats. A PSD-enriched, detergent-resistant membrane (DRM) fraction was prepared from tissue punches taken from PrL-C of adult rats and subjected to 


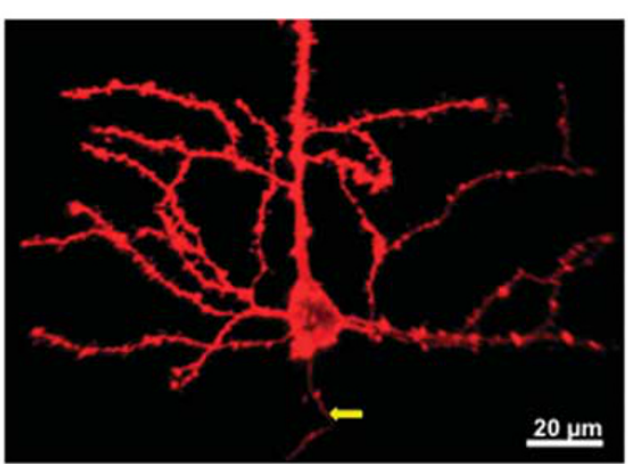

C

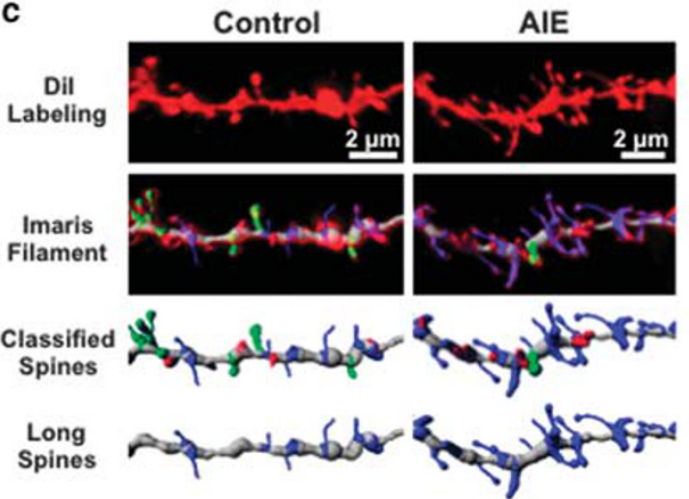

b

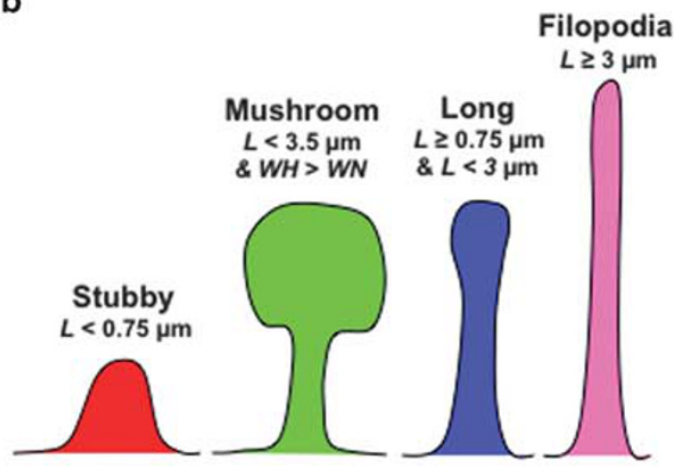

d

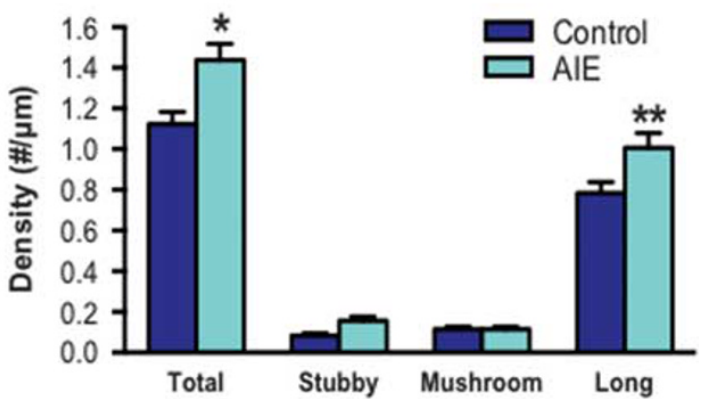

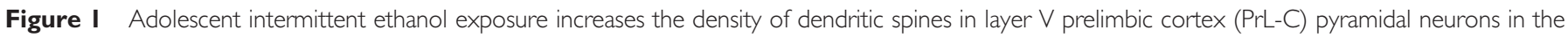

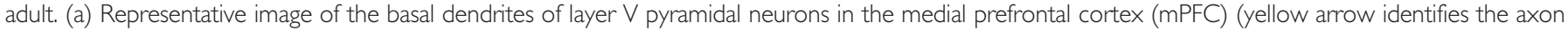

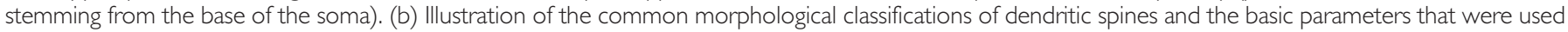

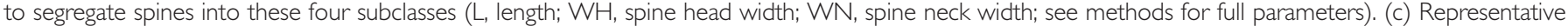

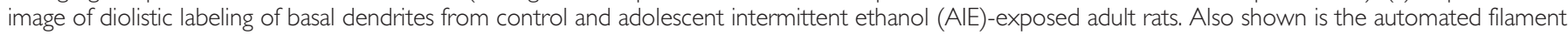

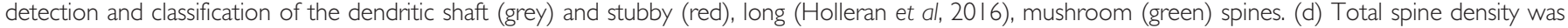

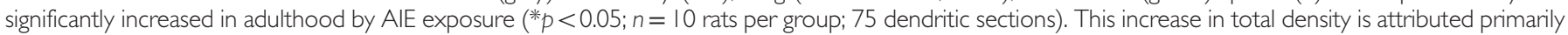
to an increase in the density of long spines (*** $p<0.001)$. All values represent the mean \pm SEM.

immunoblot analysis. The purity of this fraction was confirmed by the selective recovery of PSD-95 in the DRM fraction (Supplementary Figure S1A). Analysis of AMPA and NMDA subunit expression revealed that all of the subunits, with the exception of GluA1, were primarily located in the DRM fraction. As shown in Supplementary Figure S1B, there were no differences in the expression of AMPA and NMDA receptors or PSD-95 in the AIE-exposed adult compared with controls. These observations suggest that while AIE exposure increased the density of long spines, this was not accompanied by changes in the expression of synaptic ionotropic glutamate receptors or PSD-95.

\section{AIE Alters Tyrosine Hydroxylase and COMT Expression}

As dopaminergic innervation of the mPFC undergoes extensive developmental changes during the transition from adolescence to adulthood (Rapoport et al, 2001), the next set of studies examined the effect of AIE exposure on dopaminergic neurotransmission in the adult PrL-C. Tyrosine hydroxylase $(\mathrm{TH})$ is the rate-limiting enzyme in DA synthesis and is a useful marker of dopaminergic innervation (Nagatsu, 1995). As shown in Figures 2a and b, immunohistochemical analysis revealed that AIE exposure was associated with a significant reduction in $\mathrm{TH}$ staining in the adult PrL-C $\left(\mathrm{F}_{(1,40)}=10.4, p<0.01\right)$. These findings suggest altered dopaminergic innervation of $\mathrm{PFC}$ as a result of AIE exposure.

Owing to the sparse expression of DA transporters in the $\mathrm{PFC}$, the norepinephrine transporter (NET) and MB-COMT have a critical role in regulating extracellular concentrations of DA (Gogos et al, 1998; Kaenmaki et al, 2010). Immunohistochemical analysis revealed that AIE exposure did not alter the expression of NET in the adult PrL-C (Supplementary Figure S2A). In contrast, immunoblot analysis of MB-COMT revealed a significant reduction in expression in the tissue isolated from adult rats exposed to AIE compared with age-matched controls (Figure 2c; $\left(t_{(13)}=2.3, p<0.05\right),\left(t_{(13)}=2.3, p<0.05\right)$, respectively).

Epigenetic modifications via DNA methylation of the COMT promoter have been shown to regulate COMT expression (Ursini et al, 2011). To determine whether the reduction in expression of MB-COMT that we observed in AIE-exposed adult rats might relate to alterations in DNA methylation, DNA was extracted from PrL-C tissue punches obtained from AIEexposed and age-matched control adult rats (PD90), and the methylation at $\mathrm{CpG}$ sites of the MB-COMT promoter was examined. As depicted in Figure 3a, two methylation sites in the promoter region were analyzed: a CpG-rich site in exon I and an evolutionarily conserved CpG site in exon II that has been 
a

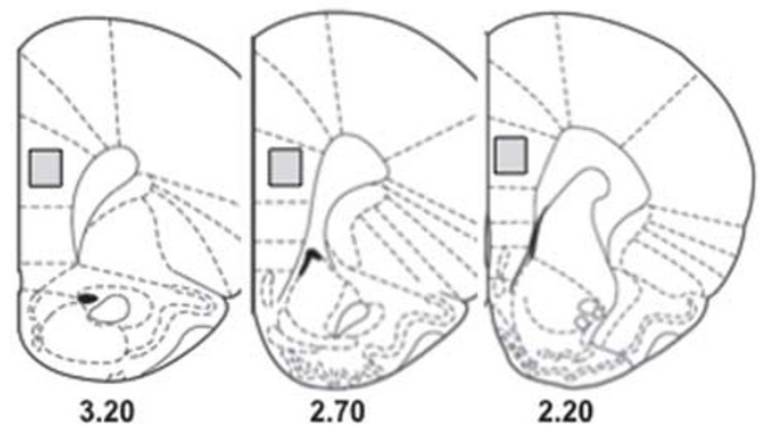

TYROSINE HYDROXYLASE

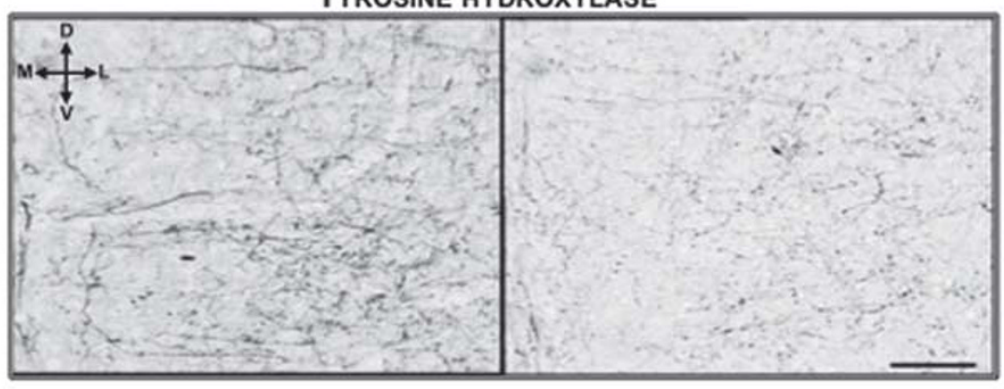

CONTROL

b

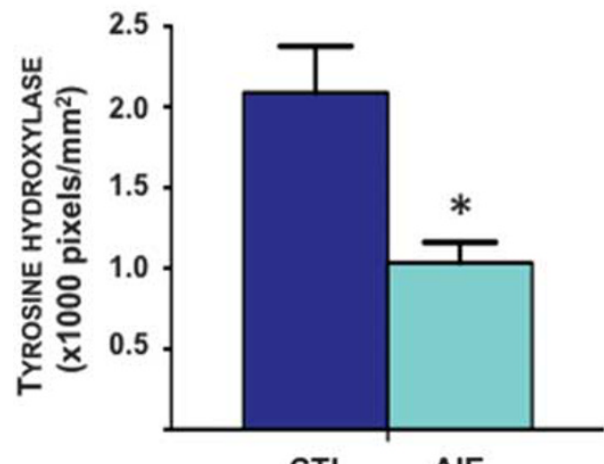

AIE

C

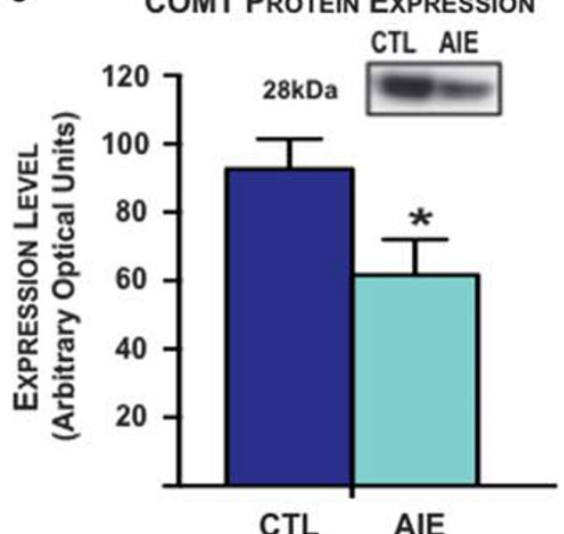

Figure 2 Adolescent intermittent ethanol exposure alters expression of dopaminergic regulatory enzymes in the adult prelimbic cortex (PrL-C). (a) Shown in the top panel is a schematic of the PrL-C. Numbers under each slice indicate distance $(\mathrm{mm})$ from bregma. The rectangle box indicates the area used for quantification of staining intensity. Bottom panel shows representative photomicrographs of tyrosine hydroxylase $(\mathrm{TH})$ staining in the PrL-C in control and adolescent intermittent ethanol (AIE)-exposed rats. Indicator in upper left comer of photomicrograph shows slice orientation ( $D$, dorsal; $L$, lateral; $M$, medial; $V$, ventral). Scale bar represents $100 \mu \mathrm{m}$. (b) Quantification of staining intensity revealed a significant reduction in the expression of TH in the adult PrL-C in AlEexposed rats compared with controls $(* p<0.05)$. (c) Representative blots of membrane-bound catechol-O-methyltransferase (MB-COMT) expression in control and AlE-exposed adult rats. AlE exposure significantly reduced MB-COMT protein expression in PrL-C of adult rats compared with age-matched control rats $(n=7-9$ rats per group; $* 2<0.05)$. All values represent the mean \pm SEM.

linked to schizophrenia (Abdolmaleky et al, 2006). As shown in Figure $3 \mathrm{~b}$, methylation analysis revealed that AIE exposure was associated with a significant increase in methylation of the conserved CpG site of exon II $\left(t_{(15)}=2.8, p<0.05\right)$. In contrast, there was no change in methylation of the CPG-rich site of exon I $\left(t_{(15)}=0.4, p=0.6\right)$.

\section{AIE Alters DA Receptor Modulation of PrL-C Pyramidal Neurons}

In light of the observed changes in DA metabolic enzymes in the AIE-exposed adult PrL-C, the next series of studies examined changes in DA receptor function via patch-clamp electrophysiology in an acute slice preparation. As DA receptor expression undergoes marked developmental changes in the PFC (Tarazi and Baldessarini, 2000; Tseng and O'Donnell, 2007), the initial set of studies characterized developmental changes in $\mathrm{D}_{1}$ and $\mathrm{D}_{2}$ modulation of evoked firing of layer $\mathrm{V}$ pyramidal neurons in slices from naive rats. As shown in Figures $4 \mathrm{a}$ and $\mathrm{b}$, bath application of the $\mathrm{D}_{1}$ receptor agonist SKF38393 $(5 \mu \mathrm{M})$ enhanced the frequency of evoked firing in slices obtained from different aged rats. However, this response to $D_{1}$ receptor stimulation was only observed in $29 \%$ of cells in slices obtained from 
a

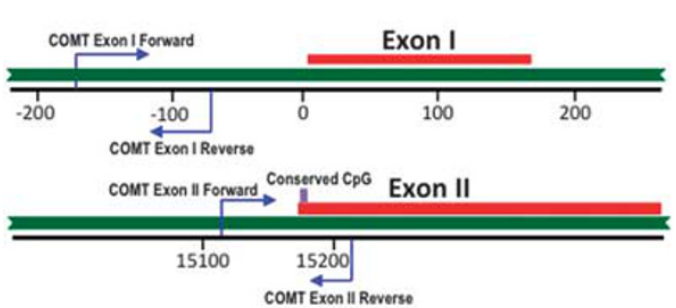

b

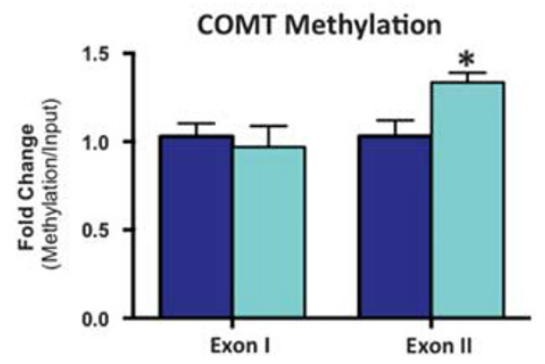

Figure 3 Adolescent alcohol exposure results in increased methylation of exon II of the catechol-O-methyltransferase (COMT) promoter in the adult prelimbic cortex (PrL-C). (a) Schematic showing the regions of interest on the COMT gene. (b) Adolescent intermittent ethanol (AIE) exposure significantly increased DNA methylation of the conserved CpG site in exon II, but had no effect on methylation of exon I ( $n=8-9$ animals per group; $* p<0.05)$. All values represent the mean \pm SEM.

preadolescent aged rats (PD14-21). In contrast, by early adolescence (PD28-35), a majority of cells (83.3\%) showed an increase in evoked firing frequency in response to $D_{1}$ receptor stimulation, and by adulthood, $100 \%$ of the recorded cells responded to $\mathrm{D}_{1}$ receptor stimulation (Figure 4a and Supplementary Table S2). Of the cells that responded, there was an increase in evoked firing frequency at all time points $\left(\mathrm{F}_{(3,16)}=6.3, p<0.005\right.$; post hoc test $p<0.05$; Figure $4 \mathrm{~b}$ and Supplementary Table S2). In contrast, bath application of the $\mathrm{D}_{2}$ agonist quinpirole $(5 \mu \mathrm{M})$ reduced the frequency of evoked firing. Similar to the $D_{1}$ developmental time course, there was a significant decrease in evoked firing following $\mathrm{D}_{2}$ receptor stimulation at the different time points $\left(\mathrm{F}_{(3,28)}=3.8, p<0.05\right)$. However, the percentage of cells in which $\mathrm{D}_{2}$ stimulation reduced firing progressively increased with age from $35.7 \%$ in slices obtained from PD14-21 to $100 \%$ of the recorded neurons in adult slices (Figure 4a). It should be noted that because of the low percentage of cells that responded to $D_{1}$ or $D_{2}$ receptor stimulation early in development, the observed interactions could be confounded by the variability in the number of cells per group. Measurement of the intrinsic properties of all cells confirmed that the population of cells that were examined was the same across all age groups and treatment conditions, and recordings were not biased toward a particular subtype of pyramidal neuron (Supplementary Table S2). These observations are in agreement with previous reports indicating that in $\mathrm{PFC}, \mathrm{D}_{1}$ and $\mathrm{D}_{2}$ receptors undergo significant developmental changes (Tarazi and Baldessarini, 2000; Brenhouse et al, 2008), and further suggests that the preadolescent/early adolescent period may be a time of especially rapid changes in DA receptor function.
The next set of studies examined the effect of AIE exposure on $\mathrm{D}_{1}$ and $\mathrm{D}_{2}$ receptor modulation of pyramidal cell firing in the adult PrL-C. As shown in Figure 5, while there were no significant differences in baseline evoked firing between the groups (Figure 5a and b), the enhancement of evoked firing in response to stimulation of $\mathrm{D}_{1}$ receptors by SKF38393 $\left(5 \mu \mathrm{M} ; t_{(8)}=5.965, p<0.001\right)$ was absent in PrL-C slices obtained from adult rats that received AIE exposure $\left(96.5 \pm 5.7 \%\right.$ of baseline; $t_{(9)}=0.5916, p=0.5727$; Figure $\left.5 c\right)$. However, immunohistochemical analysis of $\mathrm{D}_{1}$ receptor expression in PrL-C of control and AIE-exposed adult rats revealed no difference between the groups (Supplementary Figure S2B), suggesting that the reduction in $D_{1}$ receptor function was not due to a decrease in expression of the receptor. Quinpirole $(5 \mu \mathrm{M})$ stimulation of $\mathrm{D}_{2}$ receptors resulted in a significant reduction in evoked firing in PrL-C slices obtained from both control $\left(t_{(7)}=3.780, p<0.01\right)$ and AIE rats $\left(t_{(8)}=2.800, p<0.05\right.$; Figure $5 \mathrm{c}$ and Supplementary Table S2). Taken together, these observations reveal that AIE exposure resulted in the loss of $\mathrm{D}_{1}$ but not $\mathrm{D}_{2}$ receptor modulation of pyramidal neuron activity in the adult PrL-C.

The next set of studies investigated the effect of AIE exposure on DA receptor modulation of glutamatergic neurotransmission in pyramidal neurons in layer $\mathrm{V}$ of the adult PrL-C. There were no significant differences in the amplitude of eNMDA (control $59.39 \pm 6.866 \mathrm{pA}, n=12$; AIE $\left.47.98 \pm 7.408 \mathrm{pA}, n=11, t_{(21)}=1.131, p=0.2709\right)$ and eAMPA currents (control $59.83 \pm 10.12 \mathrm{pA}, n=17$; AIE $\left.50.96 \pm 10.07, n=9, t_{(24)}=0.5622, p=0.5792\right)$ and between AIE and control groups. To examine the effects of AIE on DA receptor modulation of AMPA and NMDA currents, evoked current amplitude was measured before and after bath application of SKF38393 $(5 \mu \mathrm{M})$ and quinpirole $(5 \mu \mathrm{M})$. Consistent with previous observations, pharmacological isolation of the eNMDA currents revealed a significant increase in eNMDA current amplitude in response to $D_{1}$ receptor stimulation in PrL-C slices from control rats (baseline $52.55 \pm 7.9 \mathrm{pA}$; post-SKF $74.0 \pm 11.7 \mathrm{pA}, \quad n=7$, $t_{(6)}=4.109, p<0.001$; Figure $5 \mathrm{~d}$ ). However, in keeping with the observed loss of $D_{1}$ receptor modulation of evoked firing in slices from AIE-exposed adult rats, $\mathrm{D}_{1}$ receptor modulation of NMDA currents was also absent in PrL-C slices from AIE-exposed adult rats (baseline $45.73 \pm 7.0 \mathrm{pA}$; post-SKF $\left.43.1 \pm 13.818, n=6 ; t_{(5)}=0.3439, p=0.7449\right)$. Stimulation of $\mathrm{D}_{2}$ receptors with quinpirole $(5 \mu \mathrm{M})$ decreased NMDA currents in slices from control rats and strongly attenuated NMDA currents from AIE rats, although this did not reach statistical significance $\left(t_{(4)}=1.841, p=0.0697\right)$. However, there was no significant difference in the magnitude of the effect of $\mathrm{D}_{2}$ receptor stimulation of NMDA currents between the two groups $\left(\mathrm{F}_{(1,8)}=0.8, p=0.7879\right)$.

Previous studies have shown that AMPA currents are under modulatory control by DA receptors in the mPFC (Law-Tho et al, 1994; Tseng and O'Donnell, 2004). In agreement with this, stimulation of $D_{1}$ receptors with SKF38393 $(5 \mu \mathrm{M})$ increased the amplitude of AMPA currents (control $t_{(8)}=4.125, p<0.01$; AIE $t_{(5)}=4.533, p<0.01$ ), whereas stimulation of $\mathrm{D}_{2}$ receptors with quinpirole $(5 \mu \mathrm{M})$ attenuated the amplitude of AMPA currents (CTL $t_{(7)}=2.932, p<0.05$; AIE $t_{(5)}=4.386, p<0.05$ ) (Figure 5e). However, neither $D_{1}$ or $D_{2}$ receptor modulation of AMPA 
a

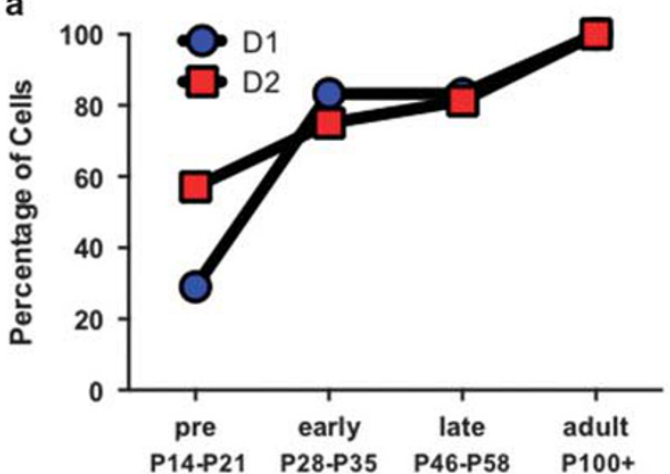

b
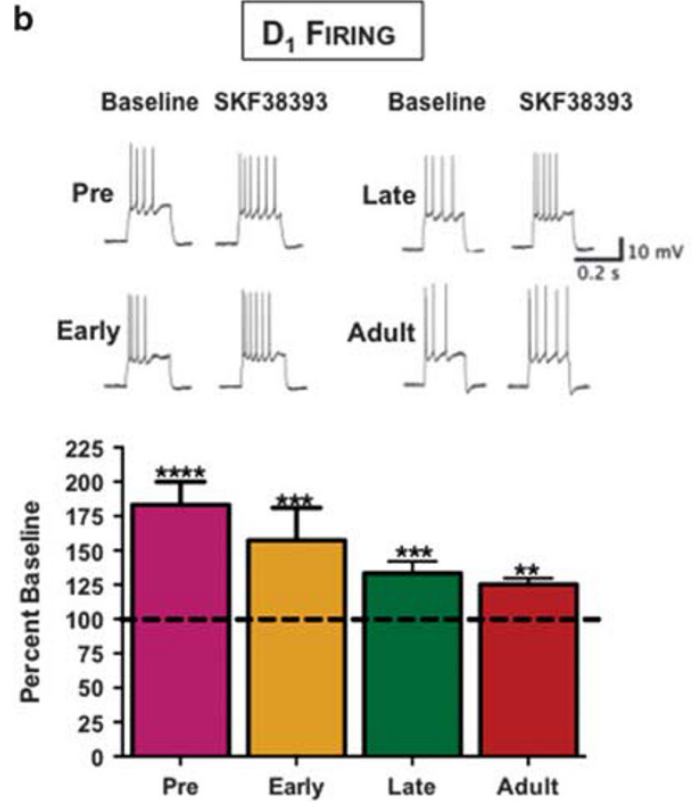

C
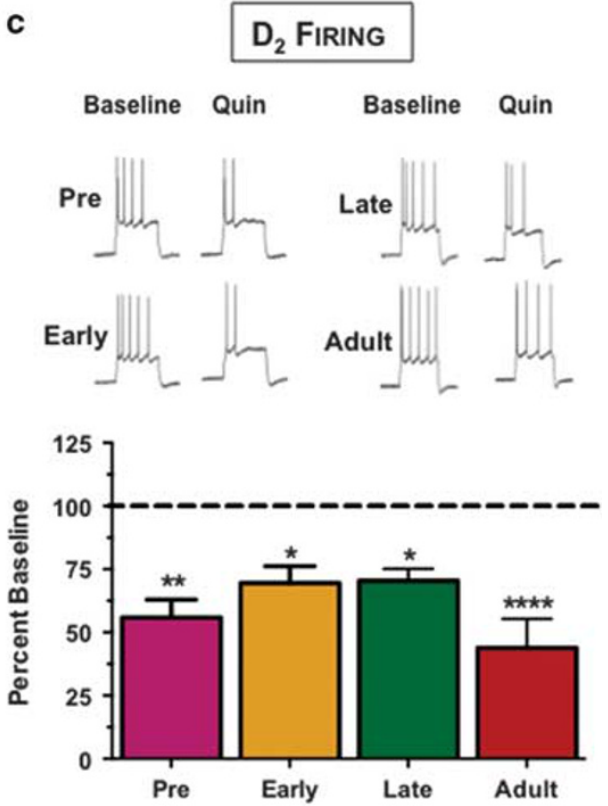

Figure 4 Developmental time course of dopamine (DA) receptor modulation of evoked firing frequency of pyramidal neurons in layer $V$ of the prelimbic cortex (PrL-C). (a) $D_{1}$ and $D_{2}$ receptor modulation of firing frequency of layer $V$ pyramidal neurons from preadolescence through adulthood. Percentage of cells that respond to $D_{1}$ (increased firing; circle) or $D_{2}$ (decreased firing; square) receptor modulation of evoked firing by the $D_{1}$ receptor agonist SKF38393 $(5 \mu \mathrm{M})$ or the $\mathrm{D}_{2}$ receptor agonist quinpirole $(5 \mu \mathrm{M})$. The four developmental age groups tested were preadolescence (PDI 4-2I), early adolescence (PD2835), late adolescence (PD46-58), and adult (>PD90). (b) Percent increase from baseline firing frequency following D, stimulation only in those cells from panel a that responded to $D_{1}$ receptor stimulation. $D_{1}$ receptor stimulation resulted in a significant increase in firing frequency in all developmental age groups ( $n=2-8$ cells per developmental age group; $* * p<0.0$ I, $* * * *<0.00 I$, and $* * * * p<0.000 I$ ). (c) $D_{2}$ receptor modulation of firing frequency in layer $V$ pyramidal neurons from preadolescence through adulthood. Shown is the percent reduction from baseline firing frequency following quinpirole only in those cells from panel a that responded to quinpirole. Bath application of quinpirole resulted in a significant reduction in evoked firing frequency at all time points ( $n=8$ cells per group; $* p<0.05, * * p<0.01$, and $* * * * *<0.000 I$ ). All values represent the mean \pm SEM.

currents was altered by AIE exposure $\left(D_{1}: F_{(1,13)}=0.3\right.$, $\left.p=0.5886 ; \mathrm{D}_{2}: \mathrm{F}_{(1,9)}=2.487, p=0.6236\right)$.

Previous work has shown that adolescence is a critical period for the development of glutamatergic and dopaminergic modulation of FSINs. In acute slices taken from control and AIE-exposed adult rats, FSINs were identified morphologically under DIC optics, physiologically by their lack of firing frequency adaption during prolonged depolarizing current steps and by their short duration action potentials, followed by a fast, large amplitude after-hyperpolarization (Supplementary Table S3). Slices from AIE-exposed adult rats exhibited lower evoked firing frequency compared with controls (for 300-400 pA steps, $p<0.05$; Figures $6 \mathrm{a}$ and $\mathrm{b}$ ). Similar to the loss of $\mathrm{D}_{1}$ receptor function that was observed in pyramidal neurons, AIE also resulted in loss of $D_{1}$ receptor-mediated enhancement of evoked firing in FSINs. In control slices, bath application of SKF38393 resulted in an enhancement of firing $\left(t_{(14)}=3.096\right.$, $p<0.05)$, but in slices obtained from AIE-exposed adult rats SKF38393 had no significant effect $\left(t_{(14)}=0.1407, p>0.05\right.$; Figure 6c). Measurement of eNMDA currents in FSINs revealed that slices from AIE-exposed rats had significantly attenuated eNMDA currents compared with controls $\left(\mathrm{F}_{(1,14)}=6.984\right.$, $p<0.05$; solid bars, Figure $6 \mathrm{~d})$. In addition, $\mathrm{D}_{1}$ receptormediated enhancement of eNMDA currents observed in slices obtained from control rats $\left(t_{(14)}=4.623, p<0.05\right)$ was significantly reduced in slices from AIE-exposed rats $\left(t_{(14)}=1.968\right.$, $p>0.05$; post-SKF values in shaded bars, Figure $6 \mathrm{~d})$. Similarly, eAMPA currents were also significantly reduced in slices from AIE rats compared with controls $\left(\mathrm{F}_{(1,14)}=5.957, p<0.05\right.$; solid bars, Figure $6 \mathrm{e})$, and $\mathrm{D}_{1}$ receptor-stimulated enhancement 


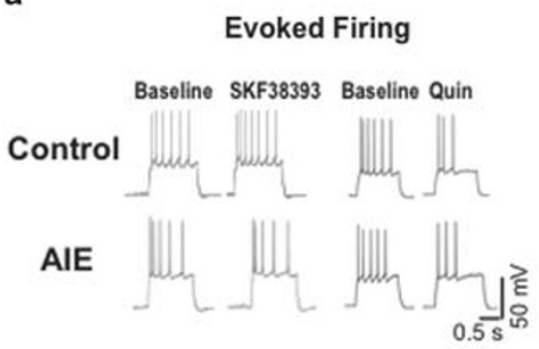

d

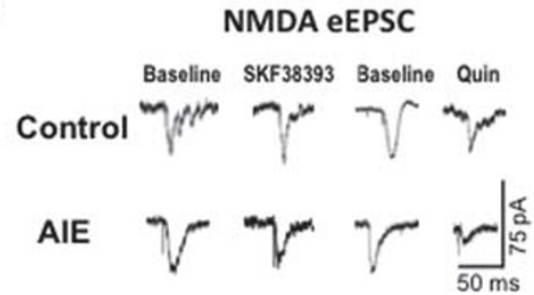

b

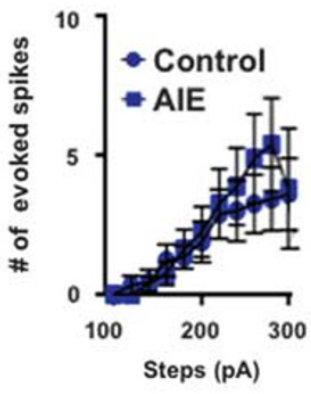

C

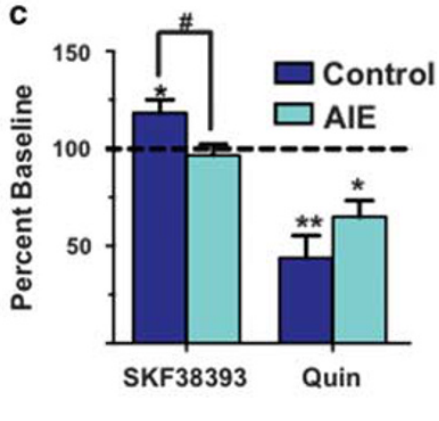

AMPA EEPSC
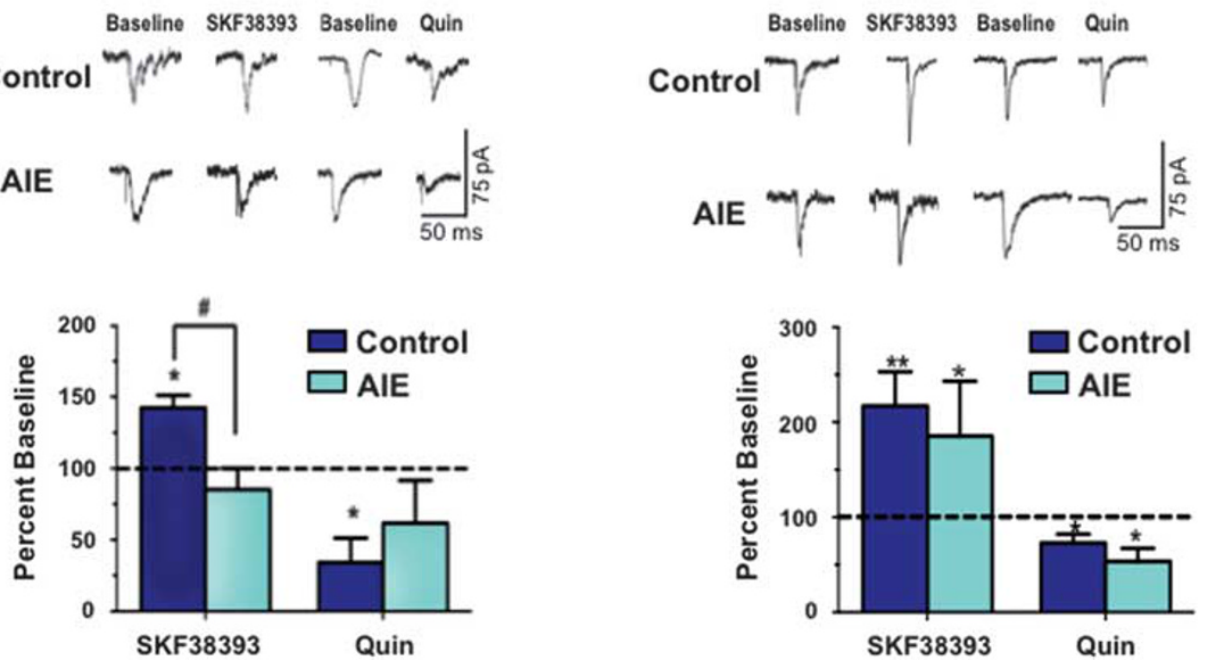

Figure 5 Adolescent intermittent ethanol exposure results in a loss of $D_{1}$ receptor modulation of firing frequency and synaptic activity of pyramidal neurons in layer $V$ of the prelimbic cortex (PrL-C). (a) Representative traces of the effect of the $D_{1}$ receptor agonist SKF38393 (5 $\left.\mu M\right)$ and the $D_{2}$ receptor agonist quinpirole $(5 \mu \mathrm{M})$ on evoked firing frequency of layer $\vee$ pyramidal neurons in PrL-C slices obtained from adult adolescent intermittent ethanol (AIE)-exposed and age-matched control rats. Top traces show firing in slices from control rats and bottom traces show firing in slices from AlE exposed rats. (b) Evoked firing frequency was not significantly different in slices from control rats compared with AlE-exposed rats. (c) In slices from control rats, SKF38393 increased evoked firing compared with baseline firing but had no effect in slices from AlE exposed rats. Bath application of quinpirole resulted in significant reduction of evoked firing in both control and AlE-exposed rats ( $n=6-10$ cells per group; $* p<0.05$ and $* * p<0.01$ for drug vs its respective baseline). (d) In slices obtained from control rats, $D$, receptor stimulation significantly increased the amplitude of eNMDA currents $(n=6-7$ cells per group, $\# p<0.0$ I, control vs AlE; $* p<0.05$, drug vs its respective baseline). This effect was not observed in slices obtained from AlE-exposed rats. $\mathrm{D}_{2}$ receptor stimulation resulted in a significant decrease in amplitude of eNMDA currents in control rats, and while slices from AlE-exposed rats showed an overall reduction in eNMDA currents in response to quinpirole, this did not reach statistical significance $(n=5-6$ cells per group, $* p<0.01)$. (e) AlE exposure did not have an effect on $D_{1}$ or $D_{2}$ receptor

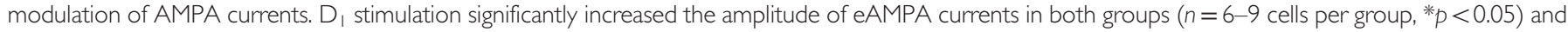
$D_{2}$ receptor stimulation significantly decreased the amplitude of evoked AMPA currents $(n=3-8$ cells per group, $* * *<<0.0$ I). All values represent the mean \pm SEM. eNMDA, evoked NMDA.

of eAMPA currents observed in slices from control adults was also attenuated in slices from AIE-exposed rats $\left(t_{(14)}=1.418\right.$, $p>0.05$; post-SKF values in shaded bars, Figure $6 \mathrm{e})$. As AIE exposure did not affect $D_{2}$ receptor modulation of pyramidal neurons, $\mathrm{D}_{2}$ receptor function was not examined in recordings from FSINs. Thus, in addition to disrupting D1 receptor modulation of pyramidal neural activity, AIE also disrupted the ability of these receptors to augment GABAergic activity. Furthermore, this was also associated with perturbation of the intrinsic excitability of PFC GABAergic interneurons.

\section{DISCUSSION}

The major finding in the present study is that binge-like alcohol exposure during adolescence results in alteration of dopaminergic neurotransmission in the PrL-C of the adult. These changes are likely associated with disruption of the normal development of the PFC. A particularly interesting observation was the AIE-associated reduction in the adult PrL-C in the expression of MB-COMT, an enzyme that is known to critically regulate DA neurotransmission in this brain region. Furthermore, this reduction in expression of MB-COMT was associated with an increase in DNA methylation at a conserved $\mathrm{CpG}$ site in the promoter region of the gene. Another interesting aspect of altered dopaminergic neurotransmission in adult rats that had been subjected to AIE exposure was a reduction in $D_{1}$ receptor modulation of both cell firing and NMDA currents in the PrL-C. This loss was also observed in both layer V pyramidal neurons and FSIN's. Moreover, the intrinsic excitability of FSIN's was also blunted by AIE. In light of the critical 
a

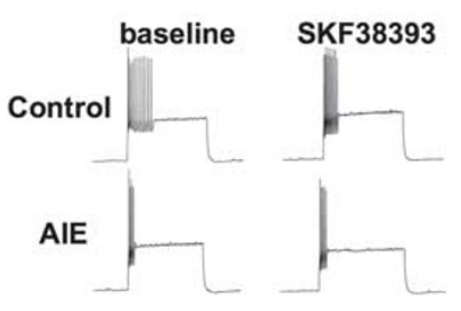

d
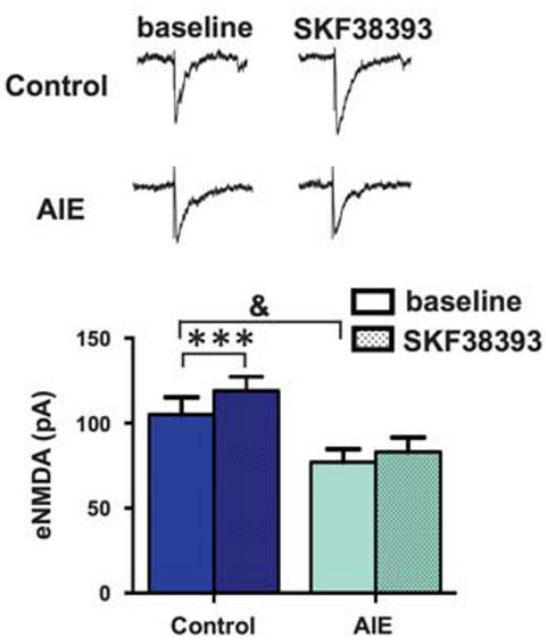

b

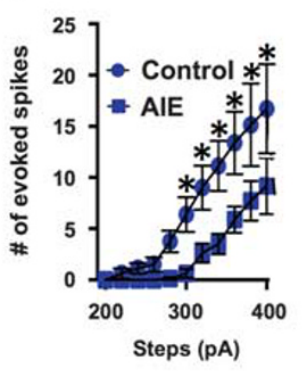

C

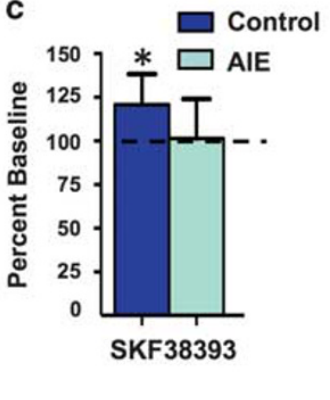

e

AMPA eEPSC
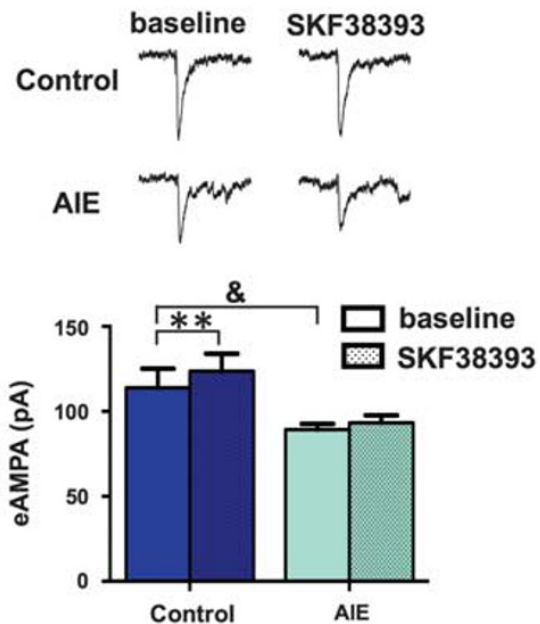

Figure 6 Adolescent intermittent ethanol exposure decreased $D$, receptor activity and evoked firing of fast-spiking interneurons (FSINs) in layer $V$ of the prelimbic cortex (PrL-C). (a) Representative traces showing evoked firing in slices from control (top traces) and adolescent intermittent ethanol (AlE)-exposed rats (bottom traces) before (baseline) and after bath application of SKF38393. (b) FSIN firing was significantly lower in slices from AlE rats compared with slices from control rats; ${ }^{*} p<0.05, n=8$ in both groups. (c) Bath application of SKF38393 resulted in an increase in FSIN firing in control rats but had no effect in slices from AIE-exposed rats. (d) eNMDA currents were significantly reduced in slices from AIE animals compared with control animals. In addition, SKF38393 significantly increased eNMDA currents in slices from control rats but has no significant effect in slices from AlE animals. (e) eAMPA currents were significantly reduced in slices from AIE-exposed rats compared with controls and bath application of SKF38393 resulted in a slight, yet statistically significant enhancement of eAMPA currents in control slices but had no effect in slices from AlE-exposed rats. Dark blue bars show data from air-exposed controls, and light green bars show data from AIE-exposed rats. Solid bars were used to show baseline evoked current amplitude, and shaded bars reflect current amplitude following bath application of SKF38393 (5 MM). * $p<0.05 * * *<0.0$ I, **** $p<0.00$ I; " between-group differences of $p<0.05 ; n=8$ cells per group. All values represent the mean \pm SEM.

role that $D_{1}$ receptors and GABAergic signaling have in the organization of neural networks in the PFC, deficits in these systems in the PrL-C of the AIE-exposed adult may underlie cognitive impairments observed in adults that abuse alcohol during adolescence.

\section{Dendritic Spines and Structural Plasticity}

Both the density of dendritic spines and their morphology are major determinants of neuronal connectivity and signal integration, and alterations in spines are widely viewed as indicators of alterations in hard wiring of circuits and functional properties. Compared with the adult PFC, the adolescent PFC has a higher density of dendritic spines and a larger population of immature spines that are thought to represent unstable and malleable synaptic connections (Dumitriu et al, 2010). During the transition to adulthood, synapses in the PFC are formed into more stable, mushroom-type spines or are pruned back as the cortical circuitry and neural networks are refined (Petanjek et al, 2011; Gourley et al, 2012). In the present study, we observed that AIE exposure resulted in an increase in the density of dendritic spines of layer $\mathrm{V}$ pyramidal neurons in the adult PrL-C. Analysis of spine morphology revealed this increase was caused by an increase in the number of long thin-type spines. This may reflect an impairment of the normal pruning process and altered structural plasticity. Furthermore, an increase in the relative density of unstable and immature spines (ie, long spines) in the AIE-exposed adult could impact and/or reflect changes in cortical function. These findings are consistent with previous studies showing that AIE exposure results in deficits in adolescent maturation of PFC (Spear and Swartzwelder, 2014).

In the $\mathrm{mPFC}, \mathrm{D}_{1}$ receptors are especially dense in the apical dendrites of layer $\mathrm{V}$ where they are localized to the perisynaptic region of thin spines (Bergson et al, 1995; 
Paspalas et al, 2013), and recent studies have shown that chronic changes in activity of $\mathrm{D}_{1}$ receptors in the PFC lead to changes in the density of these spines. For example, chronic $D_{1}$ receptor blockade has been shown to increase the density of apical spines of layer $\mathrm{V}$ pyramidal neurons in the PrL-C (Selemon et al, 2010) and stress-induced remodeling and loss of dendritic spines has been linked to downregulation of $\mathrm{D}_{1}$ receptors (Goldwater et al, 2009). A caveat to our observations of an AIE-induced increase in spine density of adult PrL layer $\mathrm{V}$ pyramidal neurons is that our analysis focused on spines on basal dendrites and not the apical dendrites and tuft region, which is the site of $D_{1}$ receptor-modulated plasticity in the studies mentioned above. The reason for our focus on basal dendrites is owing to limitations of the diolisitic labeling procedure, which resulted in inconsistent filling of the distal apical dendrites/tuft in the superficial layers. Regardless, our observations are generally consistent with studies linking bidirectional changes in $\mathrm{D}_{1}$ receptors to changes in density of thin spines of layer $\mathrm{V}$ pyramidal neurons.

\section{Expression of DA Regulatory Enzymes}

Efficient information processing by neural networks of the $\mathrm{mPFC}$ is critically dependent on DA. By modulating intrinsic cellular excitability and synaptic NMDA, AMPA, and $\mathrm{GABA}_{\mathrm{A}}$ currents, DA controls the balance between inhibitory and excitatory neurotransmission via $D_{1}$ and $D_{2}$ receptors to optimally tune neural networks (Zheng et al, 1999; Gonzalez-Islas and Hablitz, 2003; Neve et al, 2004; Tseng and O'Donnell, 2004; Trantham-Davidson et al, 2008). Unlike the striatum, where DA is primarily regulated by reuptake through the DA transporter, DAT expression in the $\mathrm{mPFC}$ is limited. Instead, the concentration of extracellular $\mathrm{DA}$ in the $\mathrm{mPFC}$ is controlled equally through reuptake by the NET and metabolism by MB-COMT (Kaenmaki et al, 2010). A previous study examining changes in mRNA in the whole brain found that levels of COMT mRNA in adult AIEexposed rats were approximately one-half of that found in naive adult rats (Coleman et al, 2011). Consistent with these observations, AIE exposure induced a reduction in MBCOMT expression in the present study. A common singlenucleotide polymorphism in the human COMT gene leads to intermediate (val/met), high (val/val), or low (met/met) activity of the enzyme and corresponding alterations in cortical DA levels (Chen et al, 2004). The activity of $\mathrm{D}_{1}$ (but not $\mathrm{D}_{2}$ ) receptors in the PFC appears to be up/downregulated in response to dopaminergic activity. Importantly, changes in $D_{1}$ receptors in the PFC have been linked to the COMT polymorphisms and differences in dopaminergic tone (Slifstein et al, 2008; Hirvonen et al, 2010). Although speculative, these observations support the suggestion that the AIE-associated reduction in COMT expression in the PFC we observed could have had a role in the reduction of $\mathrm{D}_{1}$ receptor function via promotion of a hyperdopamininergic state. This hyperdopaminergic state is consistent with a previous study showing increased basal extracellular DA in the striatum of adult rats exposed to alcohol during adolescence (Badanich et al, 2007).

MB-COMT expression is highly regulated by changes in methylation of its promoter region (Murphy et al, 2005; Abdolmaleky et al, 2006) and an increase in DNA methylation typically decreases transcription. A particularly interesting observation in the present study was enhanced methylation of exon II of the MB-COMT promoter in the adult PrL-C of AIE-exposed adult rats compared with ageand litter-matched controls. Importantly, methylation at this site has been linked to cognitive impairments observed in schizophrenia (Walton et al, 2014). Epigenetic mechanisms in the brain have been shown to be altered by alcohol exposure (Krishnan et al, 2014). Consistent with this, a recent study in humans examined methylation of the promoter region of MB-COMT in blood samples from adolescents with a history of alcohol use (van der Knaap et al, 2014). While methylation of the conserved region in exon II was not examined, their observations are consistent with our observation that adolescent alcohol exposure did not alter methylation at the CpG site of exon I. These results suggest the possibility that AIE-induced hypermethylation of exon II may be involved in decreased expression of COMT at adulthood.

In addition to a reduction in MB-COMT, AIE exposure was also associated with a decrease in the level of $\mathrm{TH}$ staining in the PrL-C. Previous studies have shown that pharmacological manipulations of DA receptors during adolescence results in marked changes in development of the DA system. In particular, stimulation of $\mathrm{D}_{2}$ receptors during this critical period reduces the expression of $\mathrm{D}_{1}$ receptor and the density of $\mathrm{TH}$ staining in the $\mathrm{mPFC}$ (Naneix et al, 2013). As TH is the rate-limiting enzyme in DA synthesis (Dickson and Briggs, 2013), a reduction in $\mathrm{TH}$ expression could reflect reduced DA synthesis in the PrL-C. However, while changes in MB-COMT and TH staining strongly suggest that AIE exposure altered dopaminergic innervation of this brain region, how these changes impact extracellular DA is not clear. Although a reduction in MB-COMT would be expected to result in reduced clearance of released DA and increased levels of extracellular $\mathrm{DA}$, a reduction of $\mathrm{TH}$ expression could have an opposing effect by reducing DA synthesis and release. Thus, while these results demonstrate that AIE exposure results in protracted changes in expression of enzymes that control DA synthesis and clearance in the PrL-C, it remains unclear how these changes may impact extracellular levels of mesocortical DA.

\section{Neurophysiological Alterations and Functional Implications}

Although it is difficult to predict the impact that AIE-mediated changes in mPFC DA regulatory enzymes will have on DA levels, AIE resulted in a reduction in D1 receptor modulation of neural activity in both pyramidal neurons and FSINs in the PrL-C. Thus, D1-mediated enhancement of neural excitability and NMDA currents was blunted in rats that had been subjected to AIE, whereas the actions of D2 receptors were relatively spared. In addition, AIE also resulted in a decrease in the excitability of FSINs, suggesting that in the adult brain, normal inhibitory transmission within the frontal lobes may be hampered after excessive exposure to alcohol during adolescence.

Our neurophysiological findings provide important insight into the pathophysiological mechanisms that may underlie 
cognitive impairment that has been associated with AIE. A considerable number of preclinical studies have revealed that AIE results in impaired prefrontal-mediated cognitive functioning that persists into adulthood, regardless of the route of exposure. For example, we recently reported that rats subjected to the same AIE procedure used here displayed impairments in set shifting (Gass et al, 2014), a form of cognitive flexibility that is critically dependent on intact D1 receptors and GABAergic transmission within the mPFC (Ragozzino, 2002; Enomoto et al, 2011). Similarly, accurate working memory performance is also dependent on PFC D1 receptors and GABA transmission (Sawaguchi et al, 1988; Seamans et al, 1998; Floresco, 2013; Auger and Floresco, 2015). Under certain conditions, this function is also impaired by AIE in a manner that may be dependent on the amount of alcohol consumed (Schulteis et al, 2008; Vargas, et al, 2014, but see Risher et al, 2015; White, et al, 2000). In addition, temporal order recognition memory is sensitive to inactivation of the mPFC (Hannesson et al, 2004), is modulated by D1 receptor activity (Lejeune et al, 2013), and is also impaired by AIE (Swartzwelder et al, 2015). The present findings suggest that impairments in numerous domains of cognition mediated by the mPFC that occur after AIE may be driven by disruptions in D1 receptor modulation of PFC neural activity and impaired the excitability of GABAergic FSINs.

D1 receptor stimulation is thought to refine cortical network activity by increasing the signal-to-noise ratio via facilitation of NMDA and GABA currents and intrinsic properties of both pyramidal neurons and FSINs, which in turn facilitate cognitive functioning (Kroner et al, 2007; Gonzalez-Burgos et al, 2005; Arnsten et al, 2015; Durstewitz and Seamans, 2002). Although we did not observe changes in overall excitability of pyramidal neurons, the AIE-induced loss of D1 receptor modulation of firing in pyramidal neurons that we observed is consistent with the idea that AIE exposure interferes with maturation of D1 signaling that is critical for supporting cognitive abilities such behavioral flexibility and inhibitory control. We observed that D1 receptor modulation of NMDA currents in pyramidal cells is selectively disrupted following AIE, while D1 receptor modulation of AMPA currents is relatively unaffected. When considered together with the IHC studies showing no overall differences in D1 receptor expression, this suggests that AIE does not result in a global loss of D1 receptors, but likely disrupts D1 receptor function by interfering with signaling specifically between D1 and NMDA receptors. Previous studies have reported that D1 receptor modulation of NMDA currents increases during late adolescence, whereas their modulation of AMPA currents remains somewhat stable during this time (Tseng and O'Donnell, 2005). In addition, D1 receptor modulation of NMDA currents occur in a circuit-specific manner because of increased expression of GluN2B receptors specifically in the apical dendrite during late adolescence, thereby selectively facilitating information flow from areas such as ventral hippocampus over other subcortical inputs (Flores-Barrera et al, 2014; Caballero et al, 2016). Taken together, these findings suggest that D1-NMDA receptor signaling is developmentally regulated, rendering this signaling pathway especially vulnerable to an environmental insult such as binge exposure to alcohol during adolescence.

The AIE-induced alterations in FSINs are particularly interesting given the important role this cell type has in shaping and synchronization of the neuronal ensembles that mediate cognitive function, and the fact that these neurons undergo marked changes in their physiology and DA responsiveness during adolescence (Kim et al, 2016; Tseng and O'Donnell, 2007). During performance of goal-directed behaviors, FSIN activity increases in a synchronous manner, and this increase is accompanied by recruitment of ensembles of synchronized, phase-locked pyramidal neurons. Importantly, performance on goaldirected tasks has been positively correlated with coordinated activation of both cell types. Moreover, optogenetically decreasing activity of FSINs also decreases phase locking of pyramidal neurons, suggesting that the networks are no longer firing synchronously, and this is accompanied by a reduction in performance on the task (Kim et al, 2016). D1 receptor stimulation has been shown to increase firing of FSINs and pyramidal neurons via enhancement of intrinsic excitability, AMPA, and NMDA currents (TranthamDavidson et al, 2014; Kruse et al, 2009). Therefore, the AIE-induced reduction in both synaptic transmission and intrinsic properties of FSINs, together with a loss of D1 receptor-facilitated recruitment of synchronized neuronal ensembles, may explain the cognitive impairments that we and others have reported previously (Schindler et al, 2014; Gass et al, 2014; Nasrallah et al, 2011; Boutros et al, 2015).

In summary, the results of the present study are the first to show that adolescent binge-like exposure to alcohol in the rat results in compromised dopaminergic function in the adult PrL-C. These changes include structural, biochemical, epigenetic, and physiological alterations that likely adversely impact DA modulation of prefrontal networks. Taken together with recent evidence that AIE exposure also alters tonic $\mathrm{GABA}_{\mathrm{A}}$ currents of layer $\mathrm{V}$ pyramidal neurons in the adult PrL-C (Centanni et al, 2016), these findings add to accumulating evidence in both animal and human studies that adolescent alcohol abuse alters normal development of the mPFC, and suggest that impairments in numerous domains of cognition mediated by this regions may be driven, at least in part, by disruptions in D1 receptor modulation of PFC neural activity and decreased excitability of GABAergic FSINs.

\section{FUNDING AND DISCLOSURE}

The authors declare no conflict of interest.

\section{ACKNOWLEDGMENTS}

We thank members of the Chandler lab for their assistance with the alcohol vapor chamber exposures. All authors report no biomedical financial interests or potential conflict of interest. This work was supported by National Institutes of Health Grants U01AA019967 (to LJC), R01AA010983 (to LJC), U24AA020022 (to FTC), F31AA022843 (to SWC), T32AA007474 (to EJG), K99AA024208 (to EJG), 
K01AA022475 (to HTD), U24AA02405 (to SCP) and VA senior research career scientist award (to SCP).

\section{REFERENCES}

Abdolmaleky HM, Cheng KH, Faraone SV, Wilcox M, Glatt SJ, Gao F et al (2006). Hypomethylation of MB-COMT promoter is a major risk factor for schizophrenia and bipolar disorder. Hum Mol Genet 15: 3132-3145.

Arnsten AF, Wang M, Paspalas CD (2015). Dopamine's actions in primate prefrontal cortex: challenges for treating cognitive disorders. Pharmacol Rev 67: 681-696.

Auger ML, Floresco SB (2015). Prefrontal cortical GABA modulation of spatial reference and working memory. Int J Neuropsychopharmacol 18: 1-10.

Badanich KA, Maldonado AM, Kirstein CL (2007). Chronic ethanol exposure during adolescence increases basal dopamine in the nucleus accumbens septi during adulthood. Alcohol Clin Exp Res 31: 895-900.

Bergson C, Mrzljak L, Smiley JF, Pappy M, Levenson R, GoldmanRakic PS (1995). Regional, cellular, and subcellular variations in the distribution of D1 and D5 dopamine receptors in primate brain. J Neurosci 15: 7821-7836.

Boutros N, Semenova S, Liu W, Crews FT, Markou A (2015). Adolescent intermittent ethanol exposure is associated with increased risky choice and decreased dopaminergic and cholinergic neuron markers in adult rats. Int J Neuropsychopharmacol 18: 1-9.

Brenhouse HC, Sonntag KC, Andersen SL (2008). Transient D1 dopamine receptor expression on prefrontal cortex projection neurons: relationship to enhanced motivational salience of drug cues in adolescence. J Neurosci 28: 2375-2382.

Caballero A, Granberg R, Tseng KY (2016). Mechanisms contributing to prefrontal cortex maturation during adolescence. Neurosci Biobehav Rev (e-pub ahead of print).

Casey BJ, Jones RM (2010). Neurobiology of the adolescent brain and behavior: implications for substance use disorders. J Am Acad Child Adolesc Psychiatry 49: 1189-1201; quiz 1285.

Centanni SW, Burnett EJ, Trantham-Davidson H, Chandler LJ (2016). Loss of delta-GABA receptor-mediated tonic currents in the adult prelimbic cortex following adolescent alcohol exposure. Addict Biol (e-pub ahead of print).

Chen J, Lipska BK, Halim N, Ma QD, Matsumoto M, Melhem S et al (2004). Functional analysis of genetic variation in catechol$O$-methyltransferase (COMT): effects on mRNA, protein, and enzyme activity in postmortem human brain. Am J Hum Genet 75: 807-821.

Coleman LG Jr., He J, Lee J, Styner M, Crews FT (2011). Adolescent binge drinking alters adult brain neurotransmitter gene expression, behavior, brain regional volumes, and neurochemistry in mice. Alcohol Clin Exp Res 35: 671-688.

Dalwani M, Sakai JT, Mikulich-Gilbertson SK, Tanabe J, Raymond K, McWilliams SK et al (2011). Reduced cortical gray matter volume in male adolescents with substance and conduct problems. Drug Alcohol Depend 118: 295-305.

De Bellis MD, Narasimhan A, Thatcher DL, Keshavan MS, Soloff P, Clark DB (2005). Prefrontal cortex, thalamus, and cerebellar volumes in adolescents and young adults with adolescent-onset alcohol use disorders and comorbid mental disorders. Alcohol Clin Exp Res 29: 1590-1600.

Dickson PW, Briggs GD (2013). Tyrosine hydroxylase: regulation by feedback inhibition and phosphorylation. Adv Pharmacol 68: $13-21$.

Dumitriu D, Hao J, Hara Y, Kaufmann J, Janssen WG, Lou W et al (2010). Selective changes in thin spine density and morphology in monkey prefrontal cortex correlate with aging-related cognitive impairment. J Neurosci 30: 7507-7515.
Durstewitz D, Seamans JK (2002). The computational role of dopamine D1 receptors in working memory. Neural Netw 15: 561-572.

Enomoto T, Tse MT, Floresco SB (2011). Reducing prefrontal gamma-aminobutyric acid activity induces cognitive, behavioral, and dopaminergic abnormalities that resemble schizophrenia. Biol Psychiatry 69: 432-441.

Flores-Barrera E, Thomases DR, Heng LJ, Cass DK, Caballero A, Tseng KY (2014). Late adolescent expression of GluN2B transmission in the prefrontal cortex is input-specific and requires postsynaptic protein kinase $\mathrm{A}$ and $\mathrm{D} 1$ dopamine receptor signaling. Biol Psychiatry 75: 508-516.

Floresco SB (2013). Prefrontal dopamine and behavioral flexibility: shifting from an 'inverted-U' toward a family of functions. Front Neurosci 7: 62.

Gass JT, Glen WB Jr., McGonigal JT, Trantham-Davidson H, Lopez MF, Randall PK et al (2014). Adolescent alcohol exposure reduces behavioral flexibility, promotes disinhibition, and increases resistance to extinction of ethanol selfadministration in adulthood. Neuropsychopharmacology 39: 2570-2583.

Gogos JA, Morgan M, Luine V, Santha M, Ogawa S, Pfaff D et al (1998). Catechol-O-methyltransferase-deficient mice exhibit sexually dimorphic changes in catecholamine levels and behavior. Proc Natl Acad Sci USA 95: 9991-9996.

Goldwater DS, Pavlides C, Hunter RG, Bloss EB, Hof PR, McEwen BS et al (2009). Structural and functional alterations to rat medial prefrontal cortex following chronic restraint stress and recovery. Neuroscience 164: 798-808.

Gonzalez-Burgos G, Kroener S, Seamans JK, Lewis DA, Barrionuevo G (2005). Dopaminergic modulation of short-term synaptic plasticity in fast-spiking interneurons of primate dorsolateral prefrontal cortex. J Neurophysiol 94: $4168-4177$.

Gonzalez-Islas C, Hablitz JJ (2003). Dopamine enhances EPSCs in layer II-III pyramidal neurons in rat prefrontal cortex. J Neurosci 23: $867-875$.

Gourley SL, Olevska A, Warren MS, Taylor JR, Koleske AJ (2012). Arg kinase regulates prefrontal dendritic spine refinement and cocaine-induced plasticity. J Neurosci 32: 2314-2323.

Hannesson DK, Howland JG, Phillips AG (2004). Interaction between perirhinal and medial prefrontal cortex is required for temporal order but not recognition memory for objects in rats. J Neurosci 24: 4596-4604.

Hirvonen MM, Nagren K, Rinne JO, Pesonen U, Vahlberg T, Hagelberg $\mathrm{N}$ et al (2010). COMT Val158Met genotype does not alter cortical or striatal dopamine D2 receptor availability in vivo. Mol Imaging Biol 12: 192-197.

Holleran KM, Wilson HH, Fetterly TL, Bluett RJ, Centanni SW, Gilfarb RA et al (2016). Ketamine and MAG lipase inhibitordependent reversal of evolving depressive behavior during forced abstinence from alcohol drinking. Neuropsychopharmacology 2062-2071.

Kaenmaki M, Tammimaki A, Myohanen T, Pakarinen K, Amberg C, Karayiorgou $\mathrm{M}$ et al (2010). Quantitative role of COMT in dopamine clearance in the prefrontal cortex of freely moving mice. J Neurochem 114: 1745-1755.

Kim H, Ahrlund-Richter S, Wang X, Deisseroth K, Carlen M (2016). Prefrontal parvalbumin neurons in control of attention. Cell 164: 208-218.

Krishnan HR, Sakharkar AJ, Teppen TL, Berkel TD, Pandey SC (2014). The epigenetic landscape of alcoholism. Int Rev Neurobiol 115: 75-116.

Kroener S, Mulholland PJ, New NN, Gass JT, Becker HC, Chandler LJ (2012). Chronic alcohol exposure alters behavioral and synaptic plasticity of the rodent prefrontal cortex. PLoS One 7: e37541. 
Kroner S, Krimer LS, Lewis DA, Barrionuevo G (2007). Dopamine increases inhibition in the monkey dorsolateral prefrontal cortex through cell type-specific modulation of interneurons. Cereb Cortex 17: 1020-1032.

Kruse MS, Premont J, Krebs MO, Jay TM (2009). Interaction of dopamine D1 with NMDA NR1 receptors in rat prefrontal cortex. Eur Neuropsychopharmacol 19: 296-304.

Law-Tho D, Hirsch JC, Crepel F (1994). Dopamine modulation of synaptic transmission in rat prefrontal cortex: an in vitro electrophysiological study. Neurosci Res 21: 151-160.

Lejeune S, Dourmap N, Martres MP, Giros B, Dauge V, Naudon L (2013). The dopamine D1 receptor agonist SKF 38393 improves temporal order memory performance in maternally deprived rats. Neurobiol Learn Mem 106: 268-273.

Murphy BC, O'Reilly RL, Singh SM (2005). Site-specific cytosine methylation in S-COMT promoter in 31 brain regions with implications for studies involving schizophrenia. Am J Med Genet $B$ 133B: 37-42.

Nagatsu T (1995). Tyrosine hydroxylase: human isoforms, structure and regulation in physiology and pathology. Essays Biochem 30: $15-35$.

Naneix F, Marchand AR, Di Scala G, Pape JR, Coutureau E (2012). Parallel maturation of goal-directed behavior and dopaminergic systems during adolescence. J Neurosci 32: 16223-16232.

Naneix F, Marchand AR, Pichon A, Pape JR, Coutureau E (2013). Adolescent stimulation of D2 receptors alters the maturation of dopamine-dependent goal-directed behavior. Neuropsychopharmacology 38: 1566-1574.

Nasrallah NA, Clark JJ, Collins AL, Akers CA, Phillips PE, Bernstein IL (2011). Risk preference following adolescent alcohol use is associated with corrupted encoding of costs but not rewards by mesolimbic dopamine. Proc Natl Acad Sci USA 108: 5466-5471.

Neve KA, Seamans JK, Trantham-Davidson H (2004). Dopamine receptor signaling. J Recept Signal Transduct Res 24: 165-205.

Paspalas CD, Wang M, Arnsten AF (2013). Constellation of HCN channels and cAMP regulating proteins in dendritic spines of the primate prefrontal cortex: potential substrate for working memory deficits in schizophrenia. Cereb Cortex 23: $1643-1654$.

Petanjek Z, Judas M, Simic G, Rasin MR, Uylings HB, Rakic P et al (2011). Extraordinary neoteny of synaptic spines in the human prefrontal cortex. Proc Natl Acad Sci USA 108: 13281-13286.

Ragozzino ME (2002). The effects of dopamine $\mathrm{D}(1)$ receptor blockade in the prelimbic-infralimbic areas on behavioral flexibility. Learn Mem 9: 18-28.

Rapoport JL, Castellanos FX, Gogate N, Janson K, Kohler S, Nelson P (2001). Imaging normal and abnormal brain development: new perspectives for child psychiatry. Aust N Z J Psychiatry 35: 272-281.

Risher ML, Fleming RL, Boutros N, Semenova S, Wilson WA, Levin $\mathrm{ED}$ et al (2015). Long-term effects of chronic intermittent ethanol exposure in adolescent and adult rats: radial-arm maze performance and operant food reinforced responding. PLoS One 8: e0140042.

Sawaguchi T, Matsumura M, Kubota K (1988). Dopamine enhances the neuronal activity of spatial short-term memory task in the primate prefrontal cortex. Neurosci Res 5: 465-473.

Schindler AG, Tsutsui KT, Clark JJ (2014). Chronic alcohol intake during adolescence, but not adulthood, promotes persistent deficits in risk-based decision making. Alcohol Clin Exp Res 38: $1622-1629$.

Schulteis G, Archer C, Tapert SF, Frank LR (2008). Intermittent binge alcohol exposure during the periadolescent period induces spatial working memory deficits in young adult rats. Alcohol 42: 459-467.

Seamans JK, Floresco SB, Phillips AG (1998). D1 receptor modulation of hippocampal-prefrontal cortical circuits integrating spatial memory with executive functions in the rat. J Neurosci 18: 1613-1621.

Selemon LD, Begovic A, Williams GV, Castner SA (2010). Reversal of neuronal and cognitive consequences of amphetamine sensitization following chronic treatment with a D1 antagonist. Pharmacol Biochem Behav 96: 325-332.

Slifstein M, Kolachana B, Simpson EH, Tabares P, Cheng B, Duvall $\mathrm{M}$ et al (2008). COMT genotype predicts cortical-limbic D1 receptor availability measured with [11C]NNC112 and PET. Mol Psychiatry 13: 821-827.

Spear LP, Swartzwelder HS (2014). Adolescent alcohol exposure and persistence of adolescent-typical phenotypes into adulthood: a mini-review. Neurosci Biobehav Rev 45: 1-8.

Swartzwelder HS, Acheson SK, Miller KM, Sexton HG, Liu W, Crews FT et al (2015). Adolescent intermittent alcohol exposure: deficits in object recognition memory and forebrain cholinergic markers. PLoS One 10: e0140042.

Tarazi FI, Baldessarini RJ (2000). Comparative postnatal development of dopamine $\mathrm{D}(1), \mathrm{D}(2)$ and $\mathrm{D}(4)$ receptors in rat forebrain. Int J Dev Neurosci 18: 29-37.

Teicher MH, Andersen SL, Hostetter JC Jr. (1995). Evidence for dopamine receptor pruning between adolescence and adulthood in striatum but not nucleus accumbens. Brain Res Dev Brain Res 89: $167-172$.

Trantham-Davidson H, Burnett EJ, Gass JT, Lopez MF, Mulholland PJ, Centanni SW et al (2014). Chronic alcohol disrupts dopamine receptor activity and the cognitive function of the medial prefrontal cortex. J Neurosci 34: 3706-3718.

Trantham-Davidson H, Kroner S, Seamans JK (2008). Dopamine modulation of prefrontal cortex interneurons occurs independently of DARPP-32. Cereb Cortex 18: 951-958.

Tse MT, Piantadosi PT, Floresco SB (2015). Prefrontal cortical gamma-aminobutyric acid transmission and cognitive function: drawing links to schizophrenia from preclinical research. Biol Psychiatry 77: 929-939.

Tseng KY, O'Donnell P (2004). Dopamine-glutamate interactions controlling prefrontal cortical pyramidal cell excitability involve multiple signaling mechanisms. $J$ Neurosci 24: 5131-5139.

Tseng KY, O'Donnell P (2005). Post-pubertal emergence of prefrontal cortical up states induced by D1-NMDA co-activation. Cereb Cortex 15: 49-57.

Tseng KY, O'Donnell P (2007). Dopamine modulation of prefrontal cortical interneurons changes during adolescence. Cereb Cortex 17: $1235-1240$.

Ursini G, Bollati V, Fazio L, Porcelli A, Iacovelli L, Catalani A et al (2011). Stress-related methylation of the catechol-O-methyltransferase Val 158 allele predicts human prefrontal cognition and activity. J Neurosci 31: 6692-6698.

van der Knaap LJ, Schaefer JM, Franken IH, Verhulst FC, van Oort FV, Riese H (2014). Catechol-O-methyltransferase gene methylation and substance use in adolescents: the TRAILS study. Genes Brain Behav 13: 618-625.

Vargas WM, Bengston L, Gilpin NW, Whitcomb BW, Richardson HN (2014). Alcohol binge drinking during adolescence or dependence during adulthood reduces prefrontal myelin in male rats. J Neurosci 34: 14777-14782.

Walton E, Liu J, Hass J, White T, Scholz M, Roessner V et al (2014). MB-COMT promoter DNA methylation is associated with working-memory processing in schizophrenia patients and healthy controls. Epigenetics 9: 1101-1107.

Welch KA, Carson A, Lawrie SM (2013). Brain structure in adolescents and young adults with alcohol problems: 
systematic review of imaging studies. Alcohol Alcohol 48: 433-444.

White AM, Ghia AJ, Levin ED, Swartzwelder HS (2000). Binge pattern ethanol exposure in adolescent and adult rats: differential impact on subsequent responsiveness to ethanol. ACER 24: 1251-1256.

Witt ED (2010). Research on alcohol and adolescent brain development: opportunities and future directions. Alcohol 44: 119-124.

Zheng P, Zhang XX, Bunney BS, Shi WX (1999). Opposite modulation of cortical $N$-methyl-D-aspartate receptor-mediated responses by low and high concentrations of dopamine. Neuroscience 91: 527-535.

cc) (1) (2) This work is licensed under a Creative Commons Attribution-NonCommercial-ShareAlike

International License. The images or other third party material in this article are included in the article's Creative Commons license, unless indicated otherwise in the credit line; if the material is not included under the Creative Commons license, users will need to obtain permission from the license holder to reproduce the material. To view a copy of this license, visit http://creativecommons.org/licenses/by-nc-sa/4.0/

(C) The Author(s) 2017

Supplementary Information accompanies the paper on the Neuropsychopharmacology website (http://www.nature.com/npp) 